\title{
El golpe de Estado de 1943, Perón y el problema del antisemitismo
}

\author{
Daniel LVOVICH \\ Universidad Nacional General Sarmiento y CONICET
}

En el contexto de las movilizaciones populares de los días 17 y 18 de octubre de 1945, en Buenos Aires, Córdoba y otras localidades se registraron disturbios antisemitas de magnitud. En la ocasión, el presidente de la Delegación de Asociaciones Israelitas Argentinas denunció en una carta dirigida al presidente Edelmiro Farrell:

las agresiones de palabra y de hecho de que ha sido objeto nuestra colectividad como tal el día 18 del corriente en la Capital Federal y varias localidades del interior de la República, particularmente en la ciudad de Córdoba. En Buenos Aires, desde las primeras horas de la mañana del día señalado grupos que integraban manifestaciones recorrieron las calles en actitud provocativa y a los gritos de 'mueran los judíos' sembraron impunemente la intranquilidad en los sectores judíos de la Capital (...) El Templo de la calle Paso 423 fue apedreado. Un grupo de correligionarios que se hallaban pacíficamente en su interior fue detenido por las autoridades de la Comisaría $7^{\circ}$, que penetraron en la sinagoga. Estos detenidos fueron puestos en libertad poco tiempo después. La pedrea se hizo extensiva a varios establecimientos judíos. En algunos frentes se inscribieron leyendas injuriosas e incitando a la matanza. En Villa Lynch (...) la gravedad de la demostración hostil motivó el pedido de garantías a las autoridades de esa localidad. ${ }^{1}$

En Córdoba los acontecimientos resultaron particularmente graves, ya que en esa ciudad -donde fueron atacadas además las sedes de varios partidos políticos y de los diarios liberales- fue asaltada la sinagoga y profanados los elementos del culto, además de haberse registrado ataques contra un local donde funcionaban varias instituciones judías y contra la sede del Banco Israelita. ${ }^{2}$ Estos desmanes fueron desarrollados por grupos de choque nacionalistas,

1 Nota del presidente de la DAIA Moisés Goldman al presidente Edelmiro J. Farrell, Mundo Israelita, 27 de octubre de 1945: 2.

2 “Córdoba: desmanes antisemitas", Mundo Israelita, 27 de octubre de 1945: 11. 
tal como denunció el Sindicato de Obreros de la Construcción de Córdoba, (Senkman 1983: 74).

Las agresiones antisemitas fueron repudiadas por el ministro de Guerra, general Humberto Sosa Molina -una de las figuras más próximas a Perón- y por el diario peronista La Época. Este periódico publicó un enérgico repudio a dichos desmanes, por los que acusaba a la infiltración en las columnas obreras de elementos "notoriamente nazifascistas (...) que las democracias han derrotado y aplastado en su tierra de origen". La nota del diario peronista continuaba sosteniendo que:

Sabemos que los propios obreros serán los primeros sorprendidos de semejante atropello. No es de argentinos tal salvajismo. Nuestros empleados y obreros, criados en la tolerancia de todos los credos, no pueden amparar una desviación tan criminal de los postulados que encarna el Coronel Perón y las fuerzas democráticas que lo acompañan, en su empresa de recuperación de los valores éticos de la argentinidad, de sus ideales primigenios.

A la vez que desvinculaba a los manifestantes peronistas de toda relación con el antisemitismo, el periódico llamaba a los trabajadores a evitar y castigar todo intento de infiltración. ${ }^{3}$ Por su parte, la Federación Obrera Nacional de la Industria del Vestido y Afines -organización con una muy importante participación de obreros y sastres judíos- responsabilizaba por los desmanes a "elementos reaccionarios repudiados por la clase trabajadora, aprovechando las grandes concentraciones obreras" pretendiendo desnaturalizar sus aspiraciones al imprimirles un tinte racista. ${ }^{4}$

Sin embargo, todo el espectro político del antiperonismo señalaba en sus denuncias que los sucesos antisemitas de los días 17 y 18 de octubre de 1945 -junto a otros graves acontecimientos que se sucedieron en los meses siguientes- resultaban una evidencia más acerca del carácter nazifascista del peronismo. De tal modo, para el arco de oposición al peronismo que confluyó en la Unión Democrática, la imputación de antisemitismo a sus rivales resultó una de las herramientas empleadas en la campaña electoral desarrollada con vistas a las elecciones de febrero de 1946.

Tal acusación parecía verosímil si se considera que en los meses siguientes se reiteraron los actos de violencia e intimidación contra personas e instituciones judías. En el mes de noviembre surgió de un acto peronista una columna que atacó comercios de propietarios judíos y la sede de la Sociedad Hebraica

3 "Los obreros no deben hacerle el juego al derrotado fascismo: el coronel Perón no es racista", La Época, 20 de octubre de 1945: 2.

4 La Época, 25 de octubre de 1945: 2. 
Argentina, ante la pasividad o aún la colaboración oficial, según la denuncia que el presidente de la institución elevó al Ministerio del Interior. ${ }^{5}$ Pese a que el ministro Urdapilleta emitió un comunicado en el que reconocía la gravedad del problema y prometía castigar a los responsables -a la par que desmentía las acusaciones de complicidad oficial- las acciones antisemitas no se detuvieron, registrándose graves incidentes a lo largo del mes de noviembre en distintos barrios de la Capital Federal y ciudades del interior del país (Senkman 1983: 76).

El punto de mayor gravedad se alcanzó cuando el joven estudiante de medicina Issac Frydemberg disparó contra un grupo de nacionalistas que asediaban la vivienda de su familia, dando muerte a uno de ellos (Senkman 1983: 77). El incidente colocó la problemática del antisemitismo en las primeras planas de los diarios, y a su denuncia como parte de la estrategia electoral de ambos bloques, de modo que mientras la Unión Democrática responsabilizaba a Perón por los desmanes, el bloque peronista denunciaba a la acusación como parte de una campaña de desprestigio internacional orquestada por sus adversarios. $^{6}$

La cuestión del antisemitismo se convirtió así en uno de los puntos en debate en la campaña electoral de 1945-1946. Aunque -como resulta evidente- no resultó el tópico más importante de dicha contienda, el problema del antisemitismo no estuvo ausente de aquella coyuntura y no se explica sólo por los incidentes de fines de 1945. El problema del antisemitismo en los meses inmediatamente posteriores a la finalización de la Segunda Guerra Mundial no podía sino leerse como una forma de complicidad intelectual y moral con el genocidio que se acababa de perpetrar. ${ }^{7}$ Junto a ello, explican su importancia temática el modo en que se instaló el debate sobre la "cuestión judía” en la esfera pública argentina en la década de 1930, el desarrollo de políticas genéricamente antiliberales y específicamente antisemitas por parte del gobierno militar surgido del golpe de estado de junio de 1943 y el lugar que la acusación de antisemitismo alcanzó en las estrategias con que el Departamento de Estado norteamericano pretendió deslegitimar la figura de Perón.

5 La Vanguardia, 27 de noviembre de 1945, Mundo Israelita, 24 de noviembre de 1945 y 1 de diciembre de 1945 .

6 De hecho, tanto en el programa de la Unión Democrática como en el del Partido Laborista para las elecciones del 24 de febrero de 1946 estaba presente el repudio a toda forma de racismo y discriminación, Ciria (1985: 182-184) y Pont (1984: 134-138).

7 Aunque desde 1942 la prensa argentina informó del proceso de exterminio de los judíos europeos, y no fueron pocos los actos públicos con los que desde distintos sectores de la colectividad judía y del arco antifascista se le condenó, la plena conciencia por parte de sectores amplios de la población acerca de las dimensiones reales del Holocausto parece haberse alcanzado sólo al finalizar la guerra. Lvovich y Finchelstein (2002). 
En este capítulo abordaremos estos tres factores para intentar dar cuenta del modo en que se construyó -pese a las evidencias en contra- la caracterización de Perón como antisemita. En efecto, la atribución de una identidad política plena entre Perón y los nacionalistas de la década de 1930, el hecho que éste hubiera participado en un gobierno que permitió el despliegue de prácticas y políticas autoritarias y discriminatorias por parte de importantes funcionarios y las acusaciones recibidas por parte del gobierno norteamericano resultaron factores que confluyeron para la construcción de una representación que, aunque no ajustada a la evidencia empírica, resultaría perdurable.

\section{Cuestión judía y antisemitismo en la Argentina de la década de 1930}

Aunque la presencia judía en Argentina fue objeto de abordaje -no sólo por la derecha antiliberal- como un problema desde fines del siglo XIX y los argumentos antisemitas adquirieron una notable difusión durante la Semana Trágica de 1919, la convicción acerca de la existencia de una peligrosa "cuestión judía" logró instalarse en la Argentina durante la década de 1930, en particular a partir de 1932, al calor del crecimiento de las organizaciones nacionalistas y de la expansión institucional de la Iglesia Católica. No se trataba ésta de una preocupación extendida al grueso de la población, pero sí resultó una temática que se tornó central en la retórica de la derecha en los años que estamos considerando.

El testimonio del intelectual y sacerdote católico Gustavo Franceschi al finalizar la década de 1930 resulta claro, ya que aconsejaba a quien dudara de la existencia de un problema judío:

Mirar los carteles que pululan en nuestros muros, ya acusando a los hebreos, ya defendiéndolos, y aconsejando represalias contra sus enemigos responsabilizando de todo al fascismo, y culpándolo de cuanto movimiento antisemita se realiza entre nosotros. Y la literatura que se expande en volúmenes, folletos y revistas confirma la impresión susodicha: el problema judío es agudo en la Argentina. ${ }^{8}$

El director de Criterio se refería, en definitiva, a un marcado auge de la retórica y las prácticas antisemitas y de las respuestas que ello despertó por parte de organizaciones judías y antifascistas. Como sostiene Halperin Donghi (2003: 115) aunque el antisemitismo reconoce antecedentes previos en Argen-

8 Franceschi (1939:101-105). 
tina, la crisis económica de 1930 provocó que "la noción de que no sólo la Argentina tiene un problema judío, sino que los judíos son el problema, comience a encontrar eco más allá de la antigua y la nueva derecha".

A partir del fracaso del gobierno de Uriburu y su reemplazo por el del general Justo, el nacionalismo argentino experimentó profundas transformaciones. Frustrados ante lo que entendían había sido la traición conservadora que había impedido el éxito del proyecto corporativo de Uriburu, los nacionalistas radicalizaron su crítica a la democracia y el liberalismo. En efecto, entre 1932 y 1943 el nacionalismo conoció una etapa de gran expansión, transformándose de un pequeño grupo de intelectuales convertidos en conspiradores en un movimiento militante de protesta. En una Argentina cuyos fundamentos económicos se habían visto conmovidos por la crisis económica mundial iniciada en 1929, los nacionalistas encontraron la oportunidad para criticar al liberalismo político - al que adjudicaban la responsabilidad por la situación que atravesaba el país- y dirigirse a un público más amplio dispuesto a escuchar y compartir su prédica. El antisemitismo constituyó uno de los denominadores comunes del conjunto de las organizaciones nacionalistas de las décadas de 1930 y 1940. Aunque en muy pocos casos la que se denominaba "cuestión judía" llegó a incorporarse a los textos programáticos de los grupos nacionalistas, el discurso judeófobo en su prensa, panfletos, carteles callejeros y actos públicos, y las prácticas de provocación y violencia directa contra personas e instituciones judías se tornaron una constante en el periodo analizado.

Desde una perspectiva ideológica, las acusaciones contra los judíos no presentaban novedades respecto a lo sostenido en décadas anteriores, ni demasiada originalidad en relación a las acusaciones presentes en otras latitudes. Una vez más, se sostenía que los israelitas promovían la revolución social, que controlaban todos los resortes de la economía, que complotaban por todas las vías imaginables, que dominaban la prensa y manejaban los gobiernos, que amenazaban a la integridad étnica y religiosa de la nación, que eran parásitos y usureros que usufructuaban la riqueza nacional. Como en décadas anteriores, se acusaba a los judíos a la vez por comunistas y por capitalistas y se les reprochaba a la par el cosmopolitismo y el particularismo. La novedad que este periodo ofrecería al respecto sería la intensidad de la presencia del antisemitismo en la retórica nacionalista y la crudeza de su lenguaje. Los niveles de violencia verbal alcanzados por la prensa nacionalista en este periodo -como lo testimonian entre otros los periódicos Crisol y El Pampero- y la importante circulación de publicaciones específicamente antisemitas -como la revista Clarinada- resultaban fenómenos novedosos.

En la misma dirección se ubica la intensificación del uso del antisemitismo como uno de los recursos empleados por el nacionalismo para la movilización política. Resulta paradigmático al respecto el caso de Manuel Fresco. Mientras se 
desempeñó como gobernador conservador de Buenos Aires (1936-1940), Fresco no demostró la menor señal de animadversión contra los israelitas, y su gabinete contaba con funcionarios judíos; pese a que participaba de actos nacionalistas y elogiaba en discursos públicos "la mano recia y firme de dos conductores de pueblos: Hitler y Mussolini". ${ }^{9}$ Verdadero campeón del fraude y crítico infatigable de la ley Saénz Peña, Fresco había puesto en práctica en su gestión varias de las medidas anheladas por los nacionalistas: la prohibición del Partido Comunista, fórmulas de intervención del Estado en áreas sociales y laborales, y el establecimiento de la educación religiosa obligatoria en las escuelas de toda la provincia.

Tras la intervención federal de la provincia de Buenos Aires dispuesta por el presidente Ortiz, Fresco creó su propia agrupación: Unión Nacionalista Argentina-Patria (UNA-Patria). El tardío abandono de Fresco de las filas conservadoras no dejó de despertar los recelos nacionalistas. Entre las críticas que la prensa de esa extracción le formuló se hallaba la de haber nombrado en la Dirección General de Enseñanza, durante su gobierno, “ „...al judío entrerriano, de Villaguay, Grinsbourg”. La respuesta de Fresco confirma la plena incorporación del antisemitismo al bagaje nacionalista de comienzos de la década de 1940, ya que el ex gobernador creyó necesario excusarse, señalando "que por ese entonces el problema judío no había sido planteado por nadie en el país". El periodista que lo entrevistaba le reprochaba, en cambio:

Me permito informarle, doctor Fresco, que cuatro años antes de llegar usted a la gobernación de Buenos Aires la prensa nacionalista había planteado la gravedad del problema judío en sus diversos aspectos. Lo que resulta paradójico es que usted haya pretendido implantar la enseñanza cristiana en las escuelas entregando su dirección a judíos como Grinsbourg. Hay en esto un contrasentido que no se puede explicar por más dilectiva que ponga en ello, Doctor. ${ }^{10}$

Más allá de este intercambio, resulta claro que Manuel Fresco y sus seguidores incorporaron el antisemitismo como una parte integral de sus prácticas políticas. En los comienzos de la década de 1940 resultaba impensable intentar desarrollar una prédica nacionalista exitosa que no recurriera como arma de agitación al discurso antisemita, fuera por convicción ideológica de sus dirigentes y militantes, por una consideración oportunista derivada de lo que parecía ser un inminente triunfo del Eje en la guerra mundial o por la imposibilidad de competir exitosamente por la fidelidad del público con las otras organizaciones de extrema derecha sin recurrir a la retórica acerca del "proble-

9 Fresco (1937: 25).

10 Luna (1942: 7). 
ma judío" como una herramienta movilizadora. En muchos casos, que incluyen al de la agrupación liderada por Fresco, las prácticas de violencia e intimidación contra la población israelita se sumaban a la encendida retórica antisemita para configurar un cuadro reiteradamente denunciado por las agrupaciones antifascistas (Lvovich 2003: 339-341).

Simultáneamente, muchos sacerdotes, intelectuales y publicaciones del catolicismo argentino sostuvieron posturas antisemitas, pese a que ninguno de los actores involucrados hubiera aceptado tal calificación y a que en general los miembros de la jerarquía eclesiástica no se manifestaran públicamente a través de expresiones judeófobas.

Resultaba un denominador común de la retórica de los católicos que expresaban posturas antisemitas la denuncia del judaísmo, considerado como un enemigo que atentaba contra la homogeneidad espiritual de una nación a la que se definía como substancialmente católica. La antigua tradición antijudía del catolicismo se actualizó e incorporó elementos propios del antisemitismo político, en el seno de un espíritu de cruzada antiliberal en el que las afirmaciones sobre la existencia de un complot judío contra la nación y el catolicismo resultaban habituales en el seno de los discursos políticos y teológicos.

A ello se sumó la intensa circulación de literatura antisemita -como los apócrifos Protocolos de los Sabios de Sión o El Kahal-Oro de Hugo Wast- y las no poco frecuentes prácticas de discriminación en ámbitos estatales, para configurar un cuadro en el que el antisemitismo fue percibido como una grave amenaza (Lvovich 2003: 449-459). Ello motivó la creación de instituciones dedicadas a combatir las manifestaciones de prejuicio, segregación y violencia dirigidas contra la población judía. Una de ellas se originó en marzo de 1933 sobre la base de una comisión que organizó un acto como protesta frente a los atropellos antisemitas en Alemania. La comisión, ampliada con delegados de diversas instituciones de la comunidad judía, continuó su accionar con el nombre de "Comité contra las persecuciones de judíos en Alemania”, modificando su nombre en 1934 por el de "Comité contra el Antisemitismo", que en 1935 se transformó, ampliado por otras instituciones, en la Delegación de Asociaciones Israelitas Argentinas (DAIA). ${ }^{11}$ La otra institución, la Organización Popular contra el Antisemitismo (OPCA), siguió una trayectoria similar, ya que nacida en 1933 -con el nombre de Organización Popular contra el Fascismo y el Antisemitismo- como reacción frente a la llegada de Hitler al poder, debió dirigir sus esfuerzos al combate contra el antisemitismo en la Argentina ante la difusión del fenómeno. ${ }^{12}$

11 DAIA (1985).

12 OPCA (1941: 3) La eliminación de "antifascista" en el nombre de la entidad se debió a la intención de realizar actividades conjuntas con la DAIA sin comprometer a esta enti- 
Mientras la DAIA privilegiaba en su actuación la denuncia de las prácticas antisemitas asumiendo el rol específico de vocero de la comunidad judía, la OPCA se adscribía a una posición de izquierda, presentándose como una organización judía que se sumaba a otras expresiones populares en un combate que abarcaba no sólo al antisemitismo sino al fascismo en su conjunto. Ambas instituciones competían por la representación de la población judía de la Argentina, resultando muy poco habituales las actividades en las que participaban de manera conjunta. ${ }^{13}$ Ante similares preocupaciones, en 1937 se creó el Comité contra el Racismo y el Antisemitismo en Argentina (CCRAA), impulsado en su origen por destacados intelectuales comunistas -como parte de la línea de constitución de Frentes Populares para enfrentar al nazismo- y que logró concitar la adhesión de buena parte de la intelectualidad y la dirigencia política socialista, demócrata progresista y radical. ${ }^{14}$

A la vez, las políticas antisemitas desarrolladas por el régimen nacional socialista en Alemania y por otros gobiernos europeos reforzaron la centralidad de la temática a través de dos vías: la instalación de la "cuestión judía" como un problema de alcance universal que no podía dejar de repercutir en la Argentina, y los modos en que se desarrolló en el país la cuestión de la recepción de los refugiados israelitas europeos. En efecto, el 28 de julio de 1938 el Poder Ejecutivo emitió el decreto $\mathrm{N}^{\mathrm{o}} 8972$, con el que se remataban una serie de disposiciones adoptadas desde 1936 para impedir el ingreso de refugiados a la Argentina. ${ }^{15}$ A partir de aquel momento, cerradas las puertas del país al ingreso legal de refugiados, tal cuestión comenzó a ser considerada-como sostiene Senkman- como una cuestión de inmigrantes clandestinos. Mientras la prensa nacionalista denunciaba infatigablemente la "infiltración semita", el Poder Ejecutivo propiciaba un tratamiento policial de la cuestión, para lo que

dad con aquella posición, aunque la alianza entre ambas instituciones resultó muy efímera. Mundo Israelita, 15 de febrero de 1936: 1.

13 Otras instituciones de la comunidad israelita creadas para combatir el antisemitismo tuvieron en cambio una vida efímera, tal como en el caso de la "Comisión Popular para la ayuda a las masas judías alemanas y para la lucha contra el fascismo y el antisemitismo" y el "Comité contra las persecuciones religiosas".

14 CCRAA (1939). Para la evolución ideológica del CCRAA, Senkman, (1991: 140 y ss.) En el mismo año 1937 se creó la Liga Argentina por los Derechos Humanos, presidida en su origen por el socialista Mario Bravo, que aunque dedicada a una problemática más abarcadora, no dejó de participar en el combate contra el antisemitismo.

15 Senkman (1991:118-119). Esta disposición contradecía el compromiso que el representante argentino Tomás Le Bretón había contraído pocos días antes en la Conferencia Internacional de Evian -convocada por el presidente Rooselvet para dar solución al problema de los refugiados que se había incrementado tras la anexión de Austria al Reichacerca de la disposición de Argentina para recibir contingentes de población judía. 
contó con el apoyo de buena parte de la prensa liberal. Como tema de controversia política, de debate parlamentario o de información periodística, la cuestión de los refugiados contribuyó a colocar la cuestión judía en la esfera pública argentina desde fines de la década de 1930. La cuestión de los refugiados judíos en particular, y la del antisemitismo en general, logró transformarse en un tema de debate nacional porque conformaba uno de los más ríspidos problemas que enfrentaban a las fuerzas políticas en el seno del conflicto mayor presentado bajo la oposición entre democracia y fascismo. Y tal empleo no podía sino reaparecer cuando, en 1945, buena parte de los sectores que habían confluido anteriormente en el campo antifascista, observaron al naciente peronismo como una continuidad de su enemigo de entonces.

\section{Antiliberalismo y antisemitismo en el régimen militar de 1943-1946}

Con la llegada al poder del gobierno surgido del golpe de Estado del 4 de junio de 1943, la cuestión del antisemitismo ganaría aún más importancia, convirtiéndose en un tema de preocupación y debate para diversos actores.

La revolución fue encabezada por el general Rawson, que renunció antes de prestar juramento, y fue reemplazado por el general Pedro Pablo Ramírez, ministro de Guerra del gobierno de Castillo. Desde las primeras proclamas de los golpistas comenzó a quedar claro el carácter antiliberal y ultramontano de sus intenciones. ${ }^{16}$ Como ha sido señalado por todos los estudios que abordaron el tema, el régimen militar contó en sus primeros años con el entusiasta apoyo del conjunto de las organizaciones nacionalistas y de la enorme mayoría de la opinión católica. Sin embargo, entre junio y octubre de 1943 el gabinete de ministros -constituido casi exclusivamente por militares-albergaba en su seno tanto a nacionalistas como a liberales, que se disputaron el poder hasta octubre, cuando los primeros alcanzaron una hegemonía casi total (Rouquié 1986: II, 34-35).

En este primer periodo, el gobierno militar proscribió al comunismo y persiguió y encarceló a muchos de sus dirigentes y militantes, además de disolver la CGT No 2, constituida por socialistas y comunistas (Torre 1990:56). Simultáneamente, el general Elbio Anaya, ministro de Educación hasta octubre de

16 Rouquié (1986: II, 11). Zanatta (1999: 15) ha destacado tanto la presencia en las proclamas militares de los tópicos que por años había defendido la Iglesia Católica como el apoyo incondicional de la Iglesia al golpe de estado, del que esperaban que estableciera las bases definitivas del proyecto de una "nación católica", lo que lo lleva a afirmar que "El 4 de junio de 1943 la Iglesia alcanzó el poder". 
1943, dispuso la intervención de la Universidad Nacional del Litoral, y de la Universidad de Cuyo. Si desde el comienzo mismo del gobierno militar el Grupo de Oficiales Unidos (GOU) se había revelado como un importante factor de poder, a partir de octubre de 1943 esta logia resultó ser la fuerza hegemónica en el gobierno. ${ }^{17}$ En ese momento se integró al elenco gubernamental nacional y a las intervenciones provinciales y universitarias un nutrido grupo de militantes nacionalistas y católicos, que, como sostiene Romero, "dieron el tono al régimen militar: autoritario, antiliberal y mesiánico, obsesionado por la fundación de un orden social nuevo y por evitar el caos del comunismo que, según pensaban, sería la secuela inevitable de la posguerra. No le fue difícil a la oposición democrática identificar al gobierno militar con el nazismo" (Romero 1994: 130).

Entre los militantes nacionalistas y católicos - muchos de ellos conocidos por su furioso antisemitismo- que ocuparon cargos de relevancia en el gobierno militar se encontraban Gustavo Martínez Zuviría, Ministro de Justicia e Instrucción Pública; Federico Ibarguren, Comisionado Municipal de San Miguel de Tucumán; Alberto Baldrich, Interventor de la Provincia de Tucumán en cuyo equipo de gobierno se desempeñaron Ramón Doll y Héctor Bernardo; Bonifacio del Carril, Secretario de Interior; Mario Amadeo, Asesor Político del Ministerio de Relaciones Exteriores; Santiago de Estrada, Interventor de la Universidad de Tucumán, y Héctor Lambías, Interventor de la Facultad de Filosofía y Letras de Mendoza. Tal como ha señalado Rouquié, en este periodo se intentó "instaurar un régimen nacionalcatólico" que no correspondía solo a la afición al orden y el moralismo de los oficiales, sino a la necesidad de "dar una legitimidad ideológica al régimen de las bayonetas". Los militares confiaron a los nacionalistas y católicos el control del aparato ideológico del Estado, inaugurando un ciclo caracterizado por la restricción de las libertades y la represión intelectual y política. En este periodo fueron intervenidas las restantes Universidades y resultó expulsado un amplio grupo de profesores opositores al régimen, el gobierno disolvió los partidos políticos y prohibió la actuación de Acción Argentina, el Comité contra el Racismo y el Antisemitismo de la Argentina y otras agrupaciones antifascistas, se limitó la libertad de prensa y fue establecida la obligatoriedad de la enseñanza religiosa católica en las escuelas públicas.

A comienzos de enero de 1944 la situación internacional de la Argentina era insostenible, ya que se había tornado imposible mantener la neutralidad ante el peso de las presiones norteamericanas y el desarrollo de la guerra en Europa. Tras una serie de incidentes diplomáticos, la Argentina rompió rela-

17 Sobre el GOU, Potash, (1984 y 1986). 
ciones con el Eje el 27 de enero de 1944. La ruptura de relaciones con el Eje provocó el desplazamiento del poder de Ramírez, que fue reemplazado por Farrell. En el gabinete de Farrell notorios nacionalistas ocuparon puestos claves: los generales Perlinger, Pistarini y Peluffo ocuparon las carteras de Interior, Obras Públicas y Relaciones Exteriores respectivamente, el Ministerio de Justicia e Instrucción Pública fue ocupado por Alberto Baldrich y el Consejo Nacional de Educación por el nacionalista católico José I. Olmedo, se nombraron interventores nacionalistas en Santa Fe, Entre Ríos y otras provincias.

En los boletines del GOU y otros documentos no destinados a la difusión pública, existen evidencias de un marcado antisemitismo. En Noticias, boletín de información y propaganda que el GOU distribuía entre sus miembros desde antes del 4 de junio de 1943 y hasta febrero de 1944, se desplegaba un cerrado anticomunismo, una lectura de la modernidad como decadencia y una particular obsesión antimasónica, características todas que compartían desde hacía tiempo los católicos y nacionalistas argentinos. En el primer número de Noticias se afirmaba que "La masonería es una creación judía apoyada por fuerzas de extraordinaria importancia" a la que le atribuían secuestrar a las naciones "cobrando el tributo de su soberanía" y representar "lo antiargentino por definición". ${ }^{18}$

Esta tradicional perspectiva conspirativa se combinaba con una combinación entre antiimperialismo y antisemitismo que si era -como señaló Zanatta (1999: 27)- muy frecuente en la cultura católica argentina, resultaba omnipresente en el nacionalismo movilizador desde mediados de la década de 1930. Sin embargo, en el discurso público del gobierno militar no es posible hallar una sola expresión explícitamente antisemita. Tampoco en las decenas de expedientes del Ministerio del Interior relativos a la detención de centenares de dirigentes y militantes comunistas -que en una apreciable proporción eran judíos- existe evidencia alguna que permita sostener que la condición judía de los detenidos era un factor que hubiera intervenido en la decisión de encarcelarlos, ni ninguna mención -siquiera de carácter descriptivo- acerca de tal condición.

Por lo contrario, cuando en julio de 1943 el ministro del Interior coronel Gilbert recibió a una delegación de la DAIA que le presentó los saludos de la colectividad israelita y le informó de que “... todos sus integrantes e institucio-

18 Potash, (1944: 101 y 198-201). En un documento de análisis de la situación interna previo al golpe, el redactor del GOU hizo responsable de la crítica situación social al “... político al servicio del acaparador, de las compañías extranjeras y del comerciante judío y explotador desconsiderado" y enumera entre los sectores que operan contra la Argentina a los "políticos vendidos, diarios, judíos, personal de empresas extranjeras". 
nes se hallan firmemente dispuestos a colaborar con todas sus fuerzas en el programa de acción esbozado por el gobierno de la Nación...”, el alto funcionario garantizó a la delegación que, de acuerdo a la tradición argentina, su gobierno aseguraba los derechos de todos los habitantes de la República, sin ninguna clase de discriminación. ${ }^{19}$

Pese a la marcada filiación antisemita de muchos de los funcionarios gubernamentales, éste no resultó un aspecto central de la ideología del régimen, sino una parte integral de una concepción global antiliberal y anticomunista (Ben Dror 1997: 241). Junto a ello, las condiciones internacionales en que se desenvolvió el régimen militar resultaban completamente desfavorables para el desarrollo de un discurso público abiertamente antisemita, máxime cuando el régimen era identificado tanto por la oposición interna cuanto por el gobierno de Estados Unidos como una versión latinoamericana del nazismo.

Con la reestructuración del gabinete de Ramírez en octubre de 1943 las medidas de cariz antiliberal y ultramontano se multiplicaron. Las políticas destinadas a cercenar la libertad de prensa -como la censura previa, el cierre de agencias de prensa extranjeras y la obligación de las estaciones radio de obtener sus noticias de agencias argentinas- que afectaron al conjunto de los medios de comunicación liberales, no dejaron de tener una particular repercusión sobre la prensa israelita de Buenos Aires. Una disposición gubernamental del 11 de octubre de 1943 que ordenaba el cierre de los diarios en idisch provocó que los días 13 y 14 de octubre fuera impedida la publicación de los periódicos escritos en ese idioma. ${ }^{20} \mathrm{Al}$ día siguiente se conocía una declaración del presidente de los Estados Unidos, Roosevelt, en la que acusaba al gobierno argentino de haber adoptado “....una medida evidentemente antisemita por su naturaleza y de un carácter identificado con los más repugnantes efectos de la doctrina nazi". ${ }^{21}$ El 17 de octubre se volvió a editar la prensa judía con una carta de disculpas del ministro del Interior Gilbert dirigida al presidente de la DAIA, en la que calificaba el episodio como un lamentable error. ${ }^{22}$ Sin embargo, la recientemente creada Policía Federal continuó aplicando el decreto de 1939 que controlaba las actividades de las asociaciones extranjeras para limitar el uso del idioma idisch en asambleas públicas, concediendo los permisos al respecto sólo a la DAIA y no a las otras entidades judías cuando estas las solicitaban por su cuenta (Ben Dror 1997: 238-239).

19 "Recibió a una delegación de la DAIA el Ministro del Interior", Mundo Israelita, 17 de julio de 1943: 1.

20 "Intervino la DAIA a raíz de una medida", Mundo Israelita, 23 de octubre de 1943: 4.

21 Citado en Senkman, (1983: 70).

22 Mundo Israelita, 23 de octubre de 1943: 4. 
La prohibición del faenaje ritual en el Frigorífico Municipal de Buenos Aires, que se reiteró en Córdoba, Rosario y distintas localidades de Entre Ríos, afectó directamente a los judíos practicantes, sin que las gestiones iniciadas por la DAIA ante el gobierno nacional y los distintos gobiernos provinciales hayan resultado siempre exitosas. ${ }^{23}$ En 1944 una ordenanza municipal obligaba a los vendedores de las ferias municipales de Buenos Aires a ofrecer solamente la carne proveniente del Frigorífico Municipal. Estando prohibido en este el faenaje ritual, la medida impedía definitivamente la comercialización de carne casher, cuyos consumidores resultaban los únicos perjudicados por la disposición municipal. El responsable de la medida fue el militante católico Samuel Medrano, por entonces Secretario del Departamento Municipal de Bromatología y Abastecimiento de la Municipalidad de Buenos Aires. Pese a las gestiones de la DAIA, la prohibición subsistió a lo largo de todo el año 1944 (Ben Dror 1997: 236-237).

La designación de Gustavo Martínez Zuviría al frente del Ministerio de Justicia e Instrucción Pública despertó una marcada inquietud en los sectores liberales y laicistas y en la comunidad judía, ya que implicaba la puesta en marcha de un proyecto educativo antiliberal y ultramontano que se contraponía al pluralismo garantizado, hasta entonces, por la ley 1420 de educación común. La instauración de la enseñanza religiosa católica en las escuelas públicas en diciembre de 1943 confirmó estos temores, ya que se contraponía abiertamente al conjunto de la tradición laicista en la educación argentina. La medida contó con un apoyo casi unánime del mundo católico y nacionalista, aunque no faltaron voces católicas que llamaron a que se respetara la libertad de conciencia de los grupos no católicos de la Argentina. ${ }^{24}$ Tal como sostiene Zanatta (1999: 115), bajo la dirección de Martínez Zuviría la escuela argentina, "concebida a la manera de una enorme parroquia, fue sometida a una radical terapia confesional, que implicó una dosis creciente de represión y autoritarismo...". En este contexto, la DAIA se alineó con los sectores laicistas para exigir del Ministerio de Educación el respeto al artículo de la ley que garantizaba que los alumnos que no practicaban la religión católica recibieran, en su lugar, clases de instrucción moral y comenzó una campaña de información a

23 Mundo Israelita, 7 de agosto de 1943: 2 y 13 de noviembre de 1943: 3.

24 Sobre la instauración de la enseñanza religiosa católica obligatoria entendida como la puesta en práctica de la más reiterada reivindicación de la Iglesia Católica, ver Zanatta, (1999:109-115). Sobre las reacciones generadas por la medida, Puiggrós y Bernetti,(1993: 316-322). En relación al apoyo de los nacionalistas a la medida, Crisol, 10 de enero de 1944: 1, Clarinada, VI, 81, enero de 1944: 10, Cabildo, 29 de diciembre de 1943: 2. Sobre los llamados de Franceschi y El Pueblo a que se respetara la libertad de conciencia de los grupos no católicos, Senkman (1983: 72). 
los padres para que dejaran constancia de que no deseaban que sus hijos recibieran instrucción religiosa católica. Sin embargo, rápidamente se multiplicaron las denuncias sobre hechos antisemitas en escuelas públicas. ${ }^{25} \mathrm{El}$ problema no se agotaba, por lo demás, en la libertad de conciencia de los niños y jóvenes no católicos, ya que suponía la introducción en el seno mismo de la escuela pública de una división hasta el momento inexistente.

Durante el periodo en que ocuparon el Ministerio de Instrucción Pública Martínez Zuviría y su sucesor Alberto Baldrich el Consejo Nacional de Educación (CNE) suspendió el tratamiento de las solicitudes de autorización de funcionamiento presentadas por escuelas judías y la entrega de certificados de docencia para sus maestros, pese a las recomendaciones favorables elevadas por los inspectores encargados de estas funciones. Escudados en razones estatutarias, los funcionarios políticos del CNE se movieron guiados por la xenofobia y el antisemitismo para obstaculizar el funcionamiento de las escuelas judías, doce de las cuales fueron clausuradas (Zadoff 1994: 347-358).

Con la llegada de José Olmedo a la presidencia del CNE el 25 de marzo de 1944, otra figura central del catolicismo nacionalista ocupó un lugar clave en el sistema educativo argentino. La figura de Olmedo ha sido caracterizada como la un hombre de la Iglesia, dirigente de la Acción Católica y de algunas prestigiosas confraternidades, lo que no le impedía ser a la vez un ferviente sostenedor del fascismo. ${ }^{26} \mathrm{Si}$ en un comienzo la designación de Olmedo había provocado algunas fricciones con el mucho más moderado ministro Silgueira, el nombramiento de Alberto Baldrich al frente del Ministerio a comienzos de mayo de 1944 permitió la puesta en práctica de una nueva embestida antiliberal. Tradicionalista católico, sostenía Baldrich (1944: 6) en un mensaje a los estudiantes que la revolución del 4 de junio había salvado a la nación del desquicio liberal, por lo que afirmaba que quien se opusiera al régimen "conspira contra la esencia misma de la nacionalidad".

Las metas de la gestión de Baldrich y Olmedo -que permanecieron en sus cargos hasta septiembre de 1944- siguieron tres orientaciones: avanzar en el camino abierto por el decreto sobre la enseñanza religiosa intentando reformar la ley de 1420 de educación laica; sacralizar la historia patria, y organizar rápidamente la enseñanza religiosa en todas las escuelas públicas del país. Para

25 Ben Dror (1997: 235). Aun antes de la implantación de la enseñanza religiosa obligatoria Mundo Israelita informaba de que "...la DAIA ha tenido que intervenir a raíz de que en un establecimiento educacional se obliga a todos los alumnos a cumplir practicas religiosas, siendo que concurren al mismo niños que profesan distintos credos." Mundo Israelita, 7 de agosto de 1943: 2.

26 Zanatta, (1999: 175). Sobre la figura y la gestión de Olmedo, también Puiggrós y Bernetti (1993: 85) y Escudé (1990: 151-155). 
alcanzar tales objetivos, Olmedo se propuso separar de sus cargos docentes “ ...a los elementos indeseables en razón de no estar a la altura de su noble misión educativa". ${ }^{27}$ Largas listas de maestros y profesores exonerados por distintos motivos -razones de mejor servicio, inmoralidad, mal desempeño, "actividades contrarias a los principios fundamentales y permanentes de la nacionalidad"- comenzaron a poblar las páginas de la publicación oficial del $\mathrm{CNE}$, en las que los apellidos judíos resultaban muy frecuentes. ${ }^{28}$

Al año siguiente, cuando La Prensa criticó la gestión de Olmedo hizo hincapié en el antiliberalismo, autoritarismo e intolerancia que habían caracterizado su paso por el CNE, resaltando que había decretado "centenares de cesantías y exoneraciones, so pretexto de inconducta, aunque dictadas por razones ideológicas". ${ }^{29}$ Las prácticas antisemitas de Olmedo fueron destacadas por Mundo Israelita, que afirmaba que el funcionario, "tomó drásticas medidas para dejar la enseñanza Judenrein". ${ }^{30}$ Sin embargo, la plena confirmación acerca de la inspiración antisemita de las cesantías masivas de docentes judíos provino del sucesor de Olmedo al frente del CNE, Ataliva Herrera. En un "mensaje a los padres de familia" difundido por la prensa radial y escrita, Herrera se refirió a las cesantías decretadas por el anterior interventor, a las que su gestión estaba reconsiderando. Tras referirse a los casos en que la exoneración se había motivado por razones de inmoralidad, falta de conducta o por la existencia de antecedentes judiciales o policiales de los imputados, Herrera los comparaba con los docentes judíos dejados cesantes por Olmedo:

¿Es posible considerar en igualdad de condiciones a los que fueron declarados cesantes por prejuicios raciales contrarios al espíritu de nuestra Constitución y a la doctrina de la Iglesia Católica, que sostiene el Estado, y que ya han sido reincorporados, que a los exonerados por las causales anteriormente expuestas ? $^{31}$

En mayo de 1945, la DAIA continuaba intentando infructuosamente que se derogara la disposición que obligaba a solicitar autorización para el uso del idisch en actos públicos y la ordenanza que prohibía el faenaje ritual en el Matadero Municipal de Buenos Aires. En cambio, las gestiones iniciadas ante el Ministerio de Guerra para que se derogara la cláusula que exigía la presen-

27 El Monitor de la Educación Común, LXIII, 858, junio de 1944: 51.

28 Ver: Suplemento de El Monitor de la Educación Común, año LXIII, No 857, mayo de 1944: 52-62.

29 “Condenación oficial de una errónea política docente", La Prensa, 10 de junio de 1945: 8.

30 Mundo Israelita, 31 de marzo de 1945: 3.

31 El Monitor de la Educación Común, LXIV, 867 y 868, marzo y abril de 1945: 74-75. 
tación de la fe de bautismo para ingresar a las escuelas e institutos militares obtuvieron respuesta positiva en octubre de ese año. ${ }^{32}$

La provincia de Entre Ríos era una de las de mayor concentración de población judía de la Argentina, ya que fue una de las zonas en las que la Jewish Colonization Association posibilitó la instalación de inmigrantes israelitas procedentes de Europa Oriental. A partir de junio de 1943, cuando la provincia fue intervenida por el gobierno nacional, se desplegaron en ella políticas específicamente antisemitas. Tal como sostiene Senkman, se trató de la primera vez en la historia de los judíos argentinos en que desde el Estado se dispuso -durante un año y medio- retirar la personería jurídica de las asociaciones comunales, religiosas y culturales de la comunidad con el fin de clausurarlas, prohibir el faenaje de vacunos según el ritual religioso judío, suspender el funcionamiento de numerosas escuelas, agraviar verbalmente y ejercer la violencia contra colonos israelitas, discriminar a los conscriptos judíos en las efemérides patrias y decretar la cesantía de maestros y funcionarios judíos. ${ }^{33}$ Sólo desde mediados de 1945 la situación de los judíos entrerrianos y sus instituciones volvería a la normalidad.

Entre 1943 y 1946 gobernaron en Entre Ríos cuatro interventores: el coronel Ernesto Ramírez, el teniente coronel Carlos María Zavalla, el general Humberto Sosa Molina y un civil, Eduardo Francheri López (Bosch 1978: 289). Aunque bajo la intervención de Zavalla se pusieron en práctica las principales medidas antisemitas, éstas se desarrollaron desde el comienzo del gobierno de Ramírez -que anteriormente se había desempeñado por un breve periodo como jefe de policía de la capital- cuyo ministro de Gobierno era el propio Zavalla.

Las primeras medidas contrarias a la población israelita de la provincia se orientaron contra las prácticas religiosas judías. En los primeros meses de la intervención provincial fueron suspendidos algunos de los cursos religiosos israelitas en Entre Ríos y prohibido el faenaje ritual de reses, medidas que se mantuvieron por varios meses. En otros casos las medidas apuntaban a prohibir el funcionamiento mismo de las instituciones comunitarias. En septiembre de 1943 la intervención provincial cerró las escuelas de idioma y religión judías que funcionaban

32 "Intensas actividades desarrolla la DAIA", Mundo Israelita, 19 de mayo de 1945: 9 y "No será necesario ser católico para ingresar al Colegio Militar", Mundo Israelita, 27 de octubre de 1945: 2.

33 Senkman (2000: 425) El testimonio de David Blejer, quien se desempeñaría como ministro en el gobierno de Frondizi, señala que tras el golpe del 4 de junio de 1943 el gobierno de Entre Ríos prohibió el uso del idisch , cerró escuelas y sinagogas, exoneró a los empleados con apellido judío e impidió la participación de israelitas en los actos públicos. Centro de Documentación e Investigación sobre judaísmo argentino Mark Turkow. Archivo de la Palabra. Entrevista N 5, David Blejer 
en Villa Clara y Colonia Domingo Calvo, argumentando que "actuaban al margen de la reglamentación respectiva". El mismo decreto autorizaba a los inspectores escolares a informar si los establecimientos educativos judíos funcionaban de acuerdo a las disposiciones reglamentarias. ${ }^{34}$ El 20 de octubre de 1943 el gobierno provincial le retiró la personería jurídica a la Comunidad Israelita de Paraná. El pedido de revocación de la resolución oficial fue rechazado en abril de 1944 por el interventor Zavalla, que decretó la disolución de la entidad. Sólo a mediados de 1945, bajo el gobierno de Sosa Molina, se restituyó la personería a la asociación, una vez que -tal como solicitaba el interventor provincial-se reformaron los estatutos y se sustituyeron los nombres hebreos de la entidad (Senkman 2000: 426). En la misma dirección, a comienzos de 1944 fue suspendido de su puesto por el gobierno el asesor jurídico de una organización judía de Paraná, en una medida considerada antisemita por la DAIA (Ben Dror 1999: 240).

Los pequeños pueblos de las colonias sufrieron en particular el rigor de las acciones oficiales antijudías: entre julio de 1943 y agosto de 1944 fueron clausuradas escuelas y bibliotecas israelitas y disueltas sociedades culturales judías (Senkman 2000: 425).

También bajo el gobierno de Zavalla se multiplicaron las cesantías de docentes y funcionarios judíos. Desde el inicio de su intervención fueron cesados funcionarios de distintas áreas de la administración provincial y de los gobiernos municipales. En las listas de cesantes los apellidos judíos no eran los únicos, aunque constituían un grupo a todas luces sobrerrepresentado. Por otra parte, de manera simultánea el interventor aceptaba la renuncia de un amplio número de funcionarios judíos. ${ }^{35}$ Los comentarios irónicos con que el diario católico de Paraná se refería a las cesantías y renuncias no dejaban lugar a dudas acerca de la intención explícitamente racista de estas medidas. ${ }^{36}$

El 31 de agosto de 1944 el interventor del Consejo General de Educación de la Provincia de Entre Ríos dispuso la cesantía de 122 maestros judíos, en una de las medidas administrativas más abiertamente antisemitas que se hayan registrado en la historia argentina. El funcionario difundió pocos días después un comunicado en el que reseñaba los cargos que esgrimía contra seis maestras judías de Villa Domínguez: todas ellas eran acusadas de carecer de fervor patriótico y simpatizar con el comunismo. ${ }^{37}$ De manera simultánea, Zavalla

34 "Se dispone la clausura de dos escuelas", La Prensa, 26 de septiembre de 1943: 10.

35 La Acción, 21 de mayo de 1944: 1.

36 La Acción, 21 de mayo de 1944: 1.

37 En un caso, se señalaba que la docente había hecho públicas manifestaciones de repudio a la Revolución, en otro caso se señalaba la carencia de ascendiente moral de la maestra y en un tercero se hacía referencia a que la docente había manifestado en ocasión de la celebración del 12 de octubre que "por ser judía repudiaba todo intento de rememora- 
afirmaba que la cesantía de los 122 maestros tendía a lograr en el magisterio provincial "una unidad espiritual y psicológica indispensable si se quiere que la misión de la escuela sea de veras eficaz". ${ }^{38}$

Mientras ambos discursos compartían el tono antiliberal del catolicismo nacionalista, aunque omitían referirse a la medida como una expresión de antisemitismo, los comentarios de la prensa liberal remarcaban en cambio que el conjunto de los despedidos eran judíos. ${ }^{39}$ El propio Arzobispo de Paraná, Zenobio L. Guilland, debió intervenir ante el escándalo desatado por la medida, afirmando que se había enterado con desagrado de que se inculpaba a la Iglesia por "las cesantías de maestros y maestras judías" afirmando que tal imputación resultaba "injusta y absolutamente falsa" ${ }^{40}$ Pocos días después el gobierno nacional daba por terminadas las funciones de Zavalla como interventor provincial, nombrando en su reemplazo al general Humberto Sosa Molina. Aunque en el decreto no se explicaban las causas de la substitución, la prensa entrerriana informaba de que se motivaba en la "evidente y odiosa persecución racial" que se sumaba a los allanamientos a los locales de la masonería, las irregularidades en la expropiación de la usina eléctrica de Paraná y la intervención a El Diario. ${ }^{41}$

\section{El coronel Perón: entre el realismo político y las acusaciones de antisemitismo}

La llegada a la Intervención provincial de Sosa Molina, verdadera mano derecha del coronel Juan Domingo Perón, implicó un cambio profundo en relación

ción de una fecha que como la del Día de la Raza no significaba nada para nosotros" a lo que el funcionario replicaba que ello implicaba desconocer "en esa insolente forma el origen de nuestra cultura greco romana cristiana que la España misionera difundiera en estas tierras". El funcionario agregaba que la exoneración se inscribía en los postulados revolucionarios de recuperar la escuela argentina "para el mejor servicio de la Patria y Dios", tarea que requería "maestros de sólida formación moral, inmenso amor a la Patria y conocimiento exacto de las verdades de nuestra santa fe". "Dio un comunicado el Interventor en el Consejo General de Educación", La Acción, 5 de septiembre de 1944: 1; El Diario, 5 de septiembre de 1944: 5.

38 La Prensa, 6 de septiembre de 1944: 16.

39 Atalaya, 4 de septiembre de 1944: 7.

40 La Prensa, 6 de septiembre de 1944: 16 y 7 de septiembre de 1944: 8.

41 Archivo General de la Nación (AGN) (1944). Atalaya, 6 de septiembre de 1944: 1 y 8. Sobre los reclamos gremiales ante Sosa Molina por la cesantía de los 122 maestros judíos ver: La Acción, 28 de noviembre de 1944: 7; 19 de diciembre de 1944: 5. Las gestiones de la Federación de Maestros Entrerrianos también se hicieron ante la Delegación Regional de la Secretaría de Trabajo y Previsión y llegaron hasta el propio Perón. La Acción, 5 de septiembre de 1944: 6. 
con el interventor anterior, ya que uno de los objetivos fundamentales de su gestión consistía en poner fin a los excesos antiliberales y antisemitas de su antecesor. ${ }^{42}$ Tal estrategia formaba parte de la política impulsada por Perón, tendente a distanciarse del ala fascista y ultramontana del gobierno militar.

En efecto, desde el comienzo del gobierno militar el coronel Perón había construido una formidable base de poder merced a las intervenciones sobre el mundo del trabajo que había desplegado desde la Secretaría de Trabajo y Previsión y las relaciones que había logrado establecer con importantes sectores de la dirigencia sindical y de la clase obrera. ${ }^{43} \mathrm{Si}$ ello le había permitido acumular cargos cada vez más relevantes en el gobierno, Ministro de Guerra y Vicepresidente, desde los cuales disputó con éxito el poder con sus rivales nacionalistas, redefiniendo los poderes al interior del gobierno en torno a su propia figura -desde fines de 1944 reorientó el rumbo del gobierno hacia una mayor liberalización, que se articulaba con una política exterior que derivó en la declaración de guerra a Alemania y Japón del 27 de marzo de 1945.

Algunos sectores nacionalistas apoyaron las políticas laborales impulsadas por Perón desde la STP. Evidentemente, la tapa que la revista Clarinada le dedicó a Perón y las reiteradas ocasiones en que la publicación de Silveyra cubrió y elogió la obra de la Secretaría de Trabajo y Previsión, contribuyeron a conformar la imagen de Perón como un fascista. ${ }^{44}$ Sin embargo, las políticas populistas de Perón y su acercamiento a los sectores populares argentinos contrariaron a muchos otros nacionalistas (Walter 2001: 255).

En la primera mitad del año 1944 se desató una disputa por el poder en el gabinete de Farrell entre Perón y el ministro del Interior, el filofascista general Luis Perlinger. El enfrentamiento de Perón con los sectores abiertamente fascistas y antisemitas del gobierno se inspiraba en un realismo político que lo llevaba a considerar las posiciones nacionalistas como fantasiosas en el escenario abierto por el previsible triunfo aliado en la guerra. La resolución del conflicto a favor de Perón le permitió sumar el cargo de vicepresidente a los

42 Una de las primeras medidas en tal sentido de la intervención de Sosa Molina consistió en proceder, a partir del mes de octubre de 1944, a la paulatina reincorporación de los docentes judíos cesanteados por motivos raciales. Archivo Histórico de la Provincia de Entre Ríos. Consejo General de Educación de la Provincia de Entre Ríos (1944-1945). En la ocasión se reincorporaron nueve de los docentes exonerados, completándose la reincorporación del conjunto en el año 1945.

43 Ver al respecto Torre (1990); James (1990: cap. I); del Campo (1983: 119-193). Sobre la filiación ideológica de Perón, Buchrucker (1987: 301-345); sobre los contenidos del catolicismo social en su pensamiento, Zanatta (1999: 123-127).

44 Clarinada, VI, 81, enero de 1944, portada y p. 10; VII, 89, septiembre de 1944: 4; VIII, 92, diciembre de 1944: 6-13. 
que ya detentaba, y desplazar del gabinete a Perlinger, lo que arrastró a muchos militantes nacionalistas (Buchrucker 1987: 289).

Para la embajada norteamericana, el triunfo sobre Perlinger significó la derrota del ala extremista dentro del gobierno. Ya en marzo de 1944 Perón había intentado un acercamiento a la legación norteamericana, describiéndose como un "adversario de los nacionalistas" y prometiendo trabajar para el restablecimiento de un gobierno constitucional, a cambio del reconocimiento del régimen militar.

En el mismo sentido, con la ruptura de relaciones argentinas con las potencias del Eje, Perón se convirtió en el centro de la ira nacionalista. El $1^{\circ}$ de diciembre de 1944 un despacho de la embajada norteamericana en Buenos Aires daba cuenta de la abierta hostilidad entre Perón y los grupos nacionalistas. Lejos de considerarlo un fascista, todavía en marzo de 1945, la embajada norteamericana consideraba que Perón trabajaba por la celebración de elecciones democráticas que intentaría ganar con una mayoría popular (Walter 2001: 257-259).

Las relaciones entre la comunidad judía de la Argentina y el coronel Perón durante el régimen militar de 1943-1946 resultaron sumamente ambiguas. Por un lado, como buena parte de la clase media, los judíos argentinos interpretaron las iniciativas sociales que Perón desplegó desde la Secretaría de Trabajo y Previsión como medidas de tipo demagógico que tendían a la construcción de un régimen corporativista. Estas percepciones determinaron que los judíos de clase media hayan considerado a Perón un fascista y a las masas movilizadas que lo apoyaban como un peligro inminente, por lo que se alistaron en las filas de sus opositores (Senkman 1997: 179).

Sin embargo, desde mediados de 1944 Perón se había convertido en uno de los principales interlocutores a los que la DAIA recurría para denunciar las agresiones antisemitas, y ese mismo año el ascendente coronel se reunió con líderes de la comunidad judía de los Estados Unidos. En este sentido, Avni sostiene que el peligro representado por la llegada de Baldrich al Ministerio de Educación y por otros funcionarios fue mitigado por las conexiones que la DAIA estableció con Perón (Avni 1995: 205).

Durante el año 1945 Perón no sólo se desembarazó de los funcionarios más claramente identificados como antisemitas del gobierno, sino que los ministros de Educación Marina y Guerra acordaron justificar la ausencia de conscriptos y estudiantes durante las fiestas judías, así como llamar al orden a un maestro por desobedecer a esta directiva. Ese año Perón se disoció por completo de los ataques antisemitas de la Alianza Libertadora Nacionalista, mientras con anterioridad a las elecciones de febrero de 1946 la DAIA tuvo la posibilidad de emitir sus puntos de vista cinco minutos diarios por seis emisoras radiales, lo que resulta a todas luces incompatible con la imagen de un régimen antisemita. 
Sobre la base de fuentes alemanas y británicas Ignacio Klich (1992: 8-10) ha demostrado la falsedad de los documentos que pretendían relacionar a Perón con el régimen nacional socialista alemán. La etiqueta de agente nazi aplicada a Perón resultaba un corolario de los juicios que los servicios de inteligencia de Estados Unidos aplicaron al régimen de Ramírez una vez que constataron que éste no rompería relaciones con el Eje sin obtener por ello alguna recompensa en la provisión de armamentos. Sin embargo, otros países que conservaron su neutralidad no recibieron el mismo trato, lo que permite establecer que eran los intereses regionales encontrados de Estados Unidos y la Argentina los que explican la peculiar dureza de la política norteamericana en este caso. La imagen de Perón como fascista y antisemita fue reforzada por la publicación de El Libro Azul de Spruille Braden, construido sobre la base de elementos dispersos y de escaso o nulo sustento, en un intento por justificar la oposición norteamericana a Perón.

Aunque la diplomacia norteamericana buscó el apoyo británico para confirmar sus puntos de vista, Londres - cuyos intereses en Argentina divergían radicalmente de los estadounidenses- se lo negó, existiendo en cambio gran cantidad de testimonios ingleses que refutaban el carácter fascista y antisemita de Perón. ${ }^{45}$ Sin embargo, los partidarios de la Unión Democrática emplearían incansablemente el mito del carácter fascista y antisemita del peronismo como parte de su estrategia discursiva en vistas a las elecciones de 1946.

El intento estadounidense de instrumentación del antisemitismo -en un momento en que, luego del Holocausto, la opinión pública norteamericana y en particular la comunidad judía eran particularmente sensibles frente a situaciones de persecución o discriminación contra los judíos- motivó que se redoblaran los esfuerzos del gobierno argentino para derrotar al fenómeno antisemita. En tal sentido, Klich sostiene que: "Estos esfuerzos son una confirmación de la visión acertada que tenía Perón del antisemitismo como una carga onerosa que dañaba la prioridad máxima del gobierno: un modus vivendi con los Estados Unidos.” En función de tal objetivo, Perón entendía que "...debía aplacarse la inquietud de la comunidad judía del país del Norte con el fin de restarle argumentos a los funcionarios norteamericanos antiperonistas." Esto permite sostener que "la inquietud judía norteamericana fue utilizada por aquellos que deseaban el derrocamiento de Perón”.

Sin embargo, la representación de Perón como antisemita ha demostrado una marcada capacidad para perdurar en la memoria, pese a las evidencias que ha aportado la investigación histórica. ${ }^{46}$ Senkman ha demostrado que, como presidente, Perón proscribió toda forma de discriminación racial y religiosa y

45 Ver al respecto, Gravil (1995). Sobre la construcción de la imagen de un Perón fascista, Page (1999: 111-117).

46 Lvovich (2001). 
condenó públicamente al antisemitismo estatal y social, en una actitud consistente con los objetivos populistas de integración nacional y su lógica de inclusión en la comunidad nacional de todos los sectores, independientemente de sus pertenencias religiosas o étnicas. Senkman (1997: 179) afirma que la tolerancia de Perón hacia la Alianza Libertadora Nacionalista (ALN) se debió a su voluntad de emplear a esa organización como grupo de choque contra la izquierda, más allá de los contenidos antisemitas de su plataforma, señalando que el abandono de la judeofobia de la ALN se debió a la culminación de su proceso de "peronización", en el contexto de la confrontación entre el régimen y la Iglesia Católica. También Caimari (1995) cuestiona la imagen de un Perón antisemita al analizar las relaciones entre su régimen y las religiones no católicas, destacando que el respeto a todos los credos por parte de su gobierno, reforzado en particular desde 1950, resultaba un corolario de una lógica en que la única lealtad política legítima era hacia su figura y movimiento.

Por supuesto, la figura de Perón y las características de sus sucesivos gobiernos han resultado lo suficientemente ambiguos como para habilitar las más distintas lecturas. Así, resulta tan cierto que surgió de un grupo -el GOU-y un régimen -el de 1943- de nítida adscripción antisemita, como que Perón culminaría por ser una pieza clave en la neutralización de las tendencias más radicales.

$Y$ a la vez, si en los primeros años de su primer gobierno un conocido antisemita -Santiago Peralta- ocuparía la Dirección de Migraciones, ello no impidió que en aquella misma gestión se posibilitara por primera vez el acceso de judíos a funciones de importancia en el Estado, como el juez Ravobitch y el subsecretario del Ministerio del Interior Abraham Krislavin. En la misma línea, se debe señalar que Gustavo Martínez Zuviría -seguramente el primero entre los intelectuales antisemitas del nacionalismo católico- mantuvo bajo buena parte del gobierno peronista su cargo como Director de la Biblioteca Nacional. Pero no se puede obviar que la página cultural de La Prensa, cuando el matutino fue expropiado y entregado a la CGT, le fue confiada a la dirección de César Tiempo, intelectual judío que se había erigido en el principal adversario de Martínez Zuviría cuando aquél publicaba sus novelas antisemitas.

Como en otras áreas de las ideas y las prácticas de Perón, el reconocimiento de la ambigüedad y el pragmatismo parecen resultar entonces las mejores claves de lectura. No podría ser de otra manera en el caso del líder de un movimiento a la vez intensamente democratizador y fuertemente autoritario.

\section{Bibliografía y fuentes citadas}

Archivo de la Palabra del Centro de Documentación e Investigación sobre judaísmo argentino Mark Turkow. Entrevista $\mathrm{N}^{\circ}$, David Blejer. 
Archivo General de la Nación (AGN) (1944). Decreto 23485 del 4 de septiembre, Legajo 25, expediente 48.627.

Archivo Histórico de la Provincia de Entre Ríos. Consejo General de Educación de la Provincia de Entre Ríos (1944-1945): Libro de Actas 1944-1945, Acta 3296, sesión del 2 de octubre de 1944, folios 119-120.

Atlalaya (Gualeguay, Entre Ríos).

Avni, Haim (1995): “Antisemitismo en Argentina: las dimensiones del peligro". En: Senkman Leonardo / Snajder, Mario (eds.): El legado del autoritarismo: Derechos Humanos y antisemitismo en la Argentina Contemporánea. Buenos Aires: Universidad Hebrea de Jerusalén / Grupo Editor Latinoamericano, pp. 197-216.

Baldrich, Alberto (1944): La juventud argentina y la revolución del 4 de junio. Mensaje a los estudiantes argentinos transmitido por la Red Argentina de Radiodifusión, el 3 de junio de 1944. s/d.

Ben Dror, Graciela (1997): "La revolución militar, la Argentina Católica y los judíos, 1943-1945”. En: Judaica Latinoamericana III, Jerusalén, pp. 227-244.

Boletín de la Educación común (Buenos Aires).

Bosch, Beatriz (1978): Historia de Entre Ríos (1520-1969). Buenos Aires: Plus Ultra. Buchrucker, Cristian (1987): Nacionalismo y Peronismo. La Argentina en la crisis ideológica mundial (1927-1955). Buenos Aires: Sudamericana.

Caimari, Lila (1995): "Peronist Christianity and non-catholic religions: Politics and ecumenism (1943-1955)". En: Canadian Journal of Latin American and Caribbean Studies, 20, 39-40, pp. 105-125.

Ciria, Alberto (1985): Partidos y poder en la Argentina moderna (1930-1946). Buenos Aires: Hyspamérica.

Clarinada (Buenos Aires).

Comité contra el Racismo y el Antisemitismo de la Argentina (CCRAA) (1939): Dos años de labor: agosto 1937-julio 1939. Buenos Aires.

Crisol (Buenos Aires).

Del Campo, Hugo (1983): Sindicalismo y peronismo. Los comienzos de un vínculo perdurable. Buenos Aires: Clacso.

Delegación de Asociaciones Israelitas Argentinas DAIA (1985): Medio Siglo de lucha por una Argentina sin discriminaciones. Buenos Aires.

El Diario (Paraná).

Escudé, Carlos (1990): El fracaso del proyecto argentino. Educación e ideología. Buenos Aires: Tesis/Instituto Torcuato Di Tella.

Franceschi, G. (1939): “El Problema judío”. En: Criterio, 587, 1 de junio, pp. 101-105. Fresco, Manuel (1937): Mensajes y discursos politicos del Gobernador Dr. Manuel A. Fresco. La Plata: Taller de impresiones oficiales.

Gravil, Roger (1995): "El Foreign Office vs. el Departamento de Estado: reacciones británicas frente al Libro Azul'. En: Ciclos en la historia, la economía y la sociedad, Año V, 5, 9, pp. 78-88.

Halperin Donghi, Tulio (2003): La Argentina y la tormenta del mundo: Ideas e ideologías entre 1930 y 1945. Buenos Aires: Siglo XXI.

James, Daniel (1990): Resistencia e Integración. El peronismo y la clase trabajadora argentina, 1946-1976. Buenos Aires: Sudamericana. 
Klich, Ignacio (1992): "Perón, Braden y el antisemitismo: opinión pública e imagen internacional". En: Ciclos en la historia, la economía y la sociedad, II, 2, 2, pp. 5-39.

Luna, Juan José (1942): "Una accidentada entrevista con Fresco", La Voz del Plata, 12 de agosto, p. 7.

La Acción (Paraná).

La Época (Buenos Aires).

La Prensa (Buenos Aires).

La Vanguardia (Buenos Aires).

Lvovich, Daniel (2001): "Peronismo y antisemitismo: historia, memorias, mitos". En: Pablo M. Dreizik (comp.), La memoria de las cenizas. Buenos Aires: Dirección Nacional de Patrimonio, Museos y Arte de la Secretaría de Cultura de la Nación, pp. 63-72.

- (2003): Nacionalismo y Antisemitismo en la Argentina. Buenos Aires: Javier Vergara Editor-Ediciones B.

Lvovich, Daniel/Finchelstein, Federico (2002): “L'Holocauste et l'Eglise d'Argentine. Perceptions et Réactions (1933-1945)". En: Bulletin trimestriel de la Fondation Auschwitz, Bruselas, 76-77, pp. 9-30.

Mundo Israelita (Buenos Aires).

Organización Popular contra el Semitismo (OPCA) (1941): El Antisemitismo. Instrumento de los enemigos de la Patria. Buenos Aires: Alerta.

Page, Joseph (1999): Perón. Una biografía. Buenos Aires: Grijalbo Mondadori.

Pont, Elena (1984): Partido Laborista: Estado y Sindicatos. Buenos Aires: CEAL.

Potash, Robert (1984): Perón y el GOU. Los documentos de una logia secreta. Buenos Aires: Sudamericana.

- (1986): El ejército y la política en la Argentina. Buenos Aires: Hyspamérica.

Puiggrós Adriana / Bernetti, Jorge Luis (1993): Peronismo, cultura política y educación (1945-1955). Buenos Aires: Galerna.

Romero, Luis Alberto (1994): Breve historia contemporánea de la Argentina. Buenos Aires: Fondo de Cultura Económica.

Rouquié, Alain (1986): Poder militar y sociedad politica en la Argentina. Buenos Aires: Hyspamérica.

Senkman, Leonardo (1983): “El 4 de junio de 1943 y los judíos”. En: Todo es Historia, 193, p. 74.

- (1991): Argentina, la segunda guerra mundial y los refugiados indeseables. 19331945. Buenos Aires: Grupo Editor Latinoamericano.

- (1997) "The response of the first peronist government to anti-semitic discourse, 1946-1954: a necessary reassessment". En: Judaica Latinoamericana III, Jerusalén, pp. 175-206.

- (2000) "Identidades colectivas de los colonos judíos en el campo y la ciudad entrerrianos". En: Soriano Hellen (comp.): Encuentro y alteridad. Vida y cultura judia en América Latina. México: FCE/UNAM/Universidad Hebrea de Jerusalén/Asociación mexicana de amigos de la Universidad de Tel Aviv.

Torre, Juan Carlos (1990): La vieja guardia sindical y Perón. Sobre los orígenes del peronismo. Buenos Aires: Sudamericana/ Instituto Di Tella. 
Walter, Richard (2001) "La derecha y los peronistas. 1943-1955". En: McGee Deutsch Sandra / Dolkart, Ronald (comps): La derecha Argentina. Buenos Aires: Ediciones B, pp. 247-274.

Zadoff, Efraín (1994): Historia de la Educación Judia en Buenos Aires (1935-1957). Buenos Aires: Milá.

Zanatta, Loris (1999): Perón y el mito de la nación católica. Iglesia y Ejército en los orígenes del peronismo, 1943-1946. Buenos Aires: Sudamericana. 